\section{Comparação cromatográfica entre o extrato de Aspidosperma parvifoliume o fitoterápico "Pau-Pereira"}

\author{
Jácome, R.L.R.P.*; Souza, R.A., Oliveira, A.B. \\ Laboratório de Fitoquímica, Faculdade de Farmácia \\ Universidade Federal de Minas Gerais
}

\section{Resumo}

A Tintura de "pau-pereira" poderia ser produzida a partir de uma das espécies Aspidosperma parvifolium ou Geissospemun vellosii, espécies conhecidas com o nome popular de "pau-pereira". Análise por CCD e CLAE mostrou que $A$. parvifolium, uma entre várias Apocynaceae, não é ingrediente da Tintura de "pau-pereira", uma vez que o alcalóide uleína, um marcador químico da espécie, não foi detectado no fitoterápico. Poderia se tratar de G. vellossii, que possui os alcalóides gessospermina, pereirina e velosina, mas o perfil cromatográfico da tintura obtido por CLAE, sugeriu possuir principalmente polifenóis.

\section{Abstract \\ The Tincture of "Pau-Pereira" is produced from the stem bark of a plant popularly known as "pau-pereira" and supposed to be Geissospemun vellosii. Analysis by TLC and HPLC showed that Aspidosperma parvifolium, one among several Apocynaceae species popularly known as "pau-pereira", is not an ingredient of the Tincture of "Pau-Pereira" since the alkaloid uleine, a chemical marker for A. parvifolium, was not detected neither in the plant remedy nor in the stem bark used to produce it and indicated as being Geissospermum vellosii.}

O gênero Aspidosperma, pertencente à família Apocynaceae, tem sido considerado uma fonte de diferentes tipos estruturais de alcalóides indólicos ${ }^{1,2,4}$. A espécie Aspidosperma parvifolium A.DC. é uma árvore de $10-15 \mathrm{~m}$ de altura que ocorre desde o sul da Bahia até o Rio Grande do Sul, em Minas Gerais, Goiás e no Mato Grosso, sendo conhecida, popularmente, como "guatambu", "peroba" ou "pau-pereira"5. Das cascas de A. parvifolium foram isolados os alcalóides Nmetiltetraidroelipticina, uleína, epiuleína, desmetiluleína e $\operatorname{aparicina}^{1,2,3}$.

Em Belo Horizonte era comercializado o fitoterápico tintura de "pau-pereira" que, segundo a bula, correspondia à tintura das cascas de Geissospermum vellosii contendo os alcalóides pereirina, geissospermina e velosina, sendo recomendado para impaludismo, má digestão, inapetência, tontura e prisão de ventre.

Por outro lado, a denominação "pau-pereira" é dada a várias espécies do gênero Aspidosperma, incluindo $A$. parvifolium.
O presente estudo teve por objetivo, realizar uma análise comparativa entre a espécie $A$. parvifolium e o fitoterápico comercializado com o nome Tintura de "pau-pereira".

No extrato etanólico das cascas de $A$. parvifolium constatou-se a presença de alcalóides e flavonóides, enquanto que, na tintura de pau-pereira, verificou-se apenas a presença de polifenóis, diferentes de flavonóides, cumarinas e heterosídeos antracênicos.

Tabela 1. Detecção de classes de metabólitos secundários no extrato etanólico das cascas de A. parvifolium e na Tintura de "pau-pereira" por CCD

\begin{tabular}{ccc}
\hline $\begin{array}{c}\text { Classes de metabólitos } \\
\text { secundários }\end{array}$ & A. parvifolium & Fitoterápico \\
\hline Alcalóides & + & - \\
\hline Cumarinas & - & - \\
\hline Flavonóides & + & - \\
\hline Heterosídeos antracênicos & - & - \\
\hline Heterosídeos cardiotônicos & - & - \\
\hline Saponinas & - & - \\
\hline Polifenóis & - & + \\
\hline Uleína & + & - \\
\hline
\end{tabular}

Nota: (-) ausência (+) presença

No extrato alcaloídico preparado a partir das cascas de A. parvifolium observou-se, principalmente, a presença de alcalóides com Rf 0,93 e 0,83 e o extrato alcaloídico das cascas de "G. vellosii" (matéria-prima do fitoterápico) apresentou um único alcalóide de Rf 0,96. Estes resultados mostraram a ausência do alcalóide uleína na matéria prima do fitoterápico.

Tabela 2. Detecção de alcalóides nos extratos alcaloídicos das cascas de A. parvifolium e "G. vellosii" por CCD

\begin{tabular}{cc}
\hline Extratos alcaloídicos das cascas & Rf \\
\hline A. parvifolium $*$ & 0,93 e 0,83 \\
\hline G. vellosii $* *$ & 0,96 \\
\hline Uleína $^{*}$ & 0,83 \\
\hline
\end{tabular}

*coloração intensa com Dragendorff

**coloração fraca com Dragendorff

Estes resultados foram confirmados pelos cromatogramas, obtidos por CLAE, dos extratos etanólicos das duas espécies, mostrando picos com tempos de retenção bem diferentes. O cromatograma do fitoterápico mostrou picos intensos correspondentes a substâncias polares, com tempos de retenção de 2,50 (13,0\%), 3,37 (5,0\%) e 3,84 (5,0\%) minutos, enquanto que no cromatograma de $A$. parvifolium, predominaram substâncias de média polaridade com tempos de retenção de $27,48(15,0 \%)$ e 28,79 (70,0\%) minutos (figura 1). A substância, que foi identificada como sendo uleína $(0,126 \mathrm{~g})$, por comparação com amostra de referência, obtida do extrato alcaloídico, após CCD preparativa, apresentou um pico com tempo de retenção 
de 28,70 minutos (figura 2).
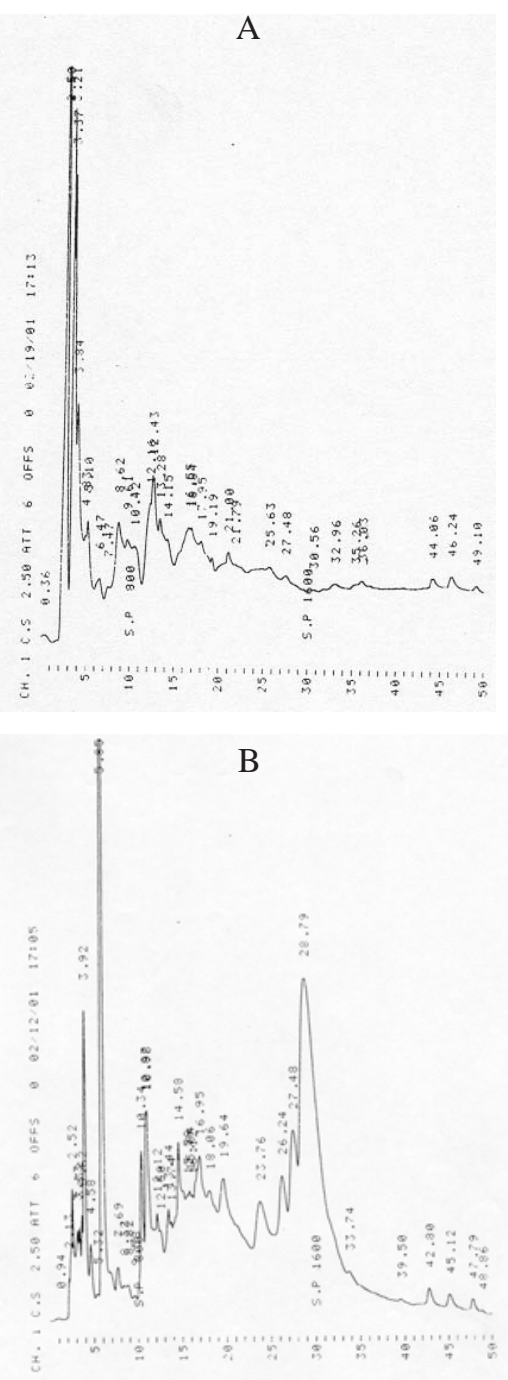

Figura1. Cromatogramas obtidos por CLAE-FR. A) Tintura de "pau-pereira"; B) Extrato etanólico de A. parvifolium. Condições cromatográficas: vide materiais e métodos.

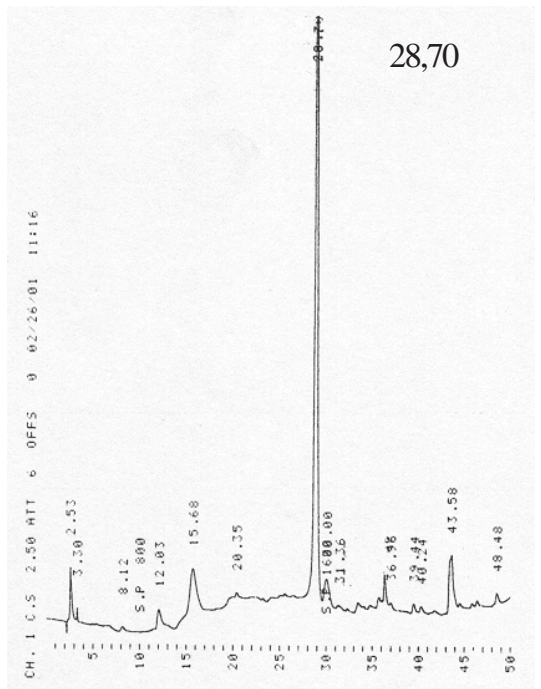

Figura 2. Cromatograma da uleína obtido por CLAE-FR. Condições cromatográficas: vide materiais e métodos
As análises por CCD e CLAE-FR mostraram que a espécie empregada na preparação da tintura de "pau-pereira" não foi A. parvifolium, uma vez que não se observou a presença de uleína, nem na matéria prima utilizada, nem no fitoterápico. O cromatograma da tintura de "pau-pereira", que deveria ter presente os alcalóides geissospermina, pereirina e velosina, possuía principalmente polifenóis.

\section{Material e Métodos}

As cascas de A. parvifolium foram coletadas na cidade de Paracatú, Minas Gerais, e foram identificadas por J. A. Lombardi, do Departamento de Botânica da Universidade Federal de Minas Gerais.

Amostras da Tintura de "pau-pereira" e, posteriormente, as cascas secas da espécie identificada pelo fornecedor como sendo Geissospermum vellosii, utilizada para a produção do fitoterápico, foram fornecidas por um laboratório de fitoterápicos.

O extrato etanólico de A. parvifolium e o fitoterápico foram analisados por cromatografia em camada delgada (CCD) de gel de sílica G6.

Tomaram-se 190,03 g das cascas pulverizadas de $A$. parvifolium que foram trituradas com $30 \mathrm{ml}$ de $\mathrm{NH}_{4} \mathrm{OH}$ concentrado e extraídas com diclorometano, em aparelho de Soxhlet, até exaustão. A solução em diclorometano foi concentrada até resíduo $(12,43 \mathrm{~g})$ e uma alíquota deste $(5,0 \mathrm{~g})$ foi cromatografada em coluna de gel de sílica, separando-se várias frações, que foram submetidas à cromatografia em camada delgada preparativa, isolando uma substância, que foi identificada como uleína, conforme comparação com amostra de referência ${ }^{3}$.

Tomaram-se 16,67 g de cascas fornecidas pelo comerciante como sendo de "G. vellosii", previamente pulverizadas, que foram trituradas com $5 \mathrm{ml}$ de $\mathrm{NH}_{4} \mathrm{OH}$ concentrado e extraídas, em aparelho de Soxhlet, com diclorometano obtendo-se, após remoção do solvente, um resíduo de $0,208 \mathrm{~g}$.

Os extratos alcaloídicos das cascas de A. parvifolium e "G. vellosii" (matéria prima do fitoterápico) também foram comparados por CCD empregando-se o reagente de Dragendorff como revelador ${ }^{6}$.

Pesaram-se 3,0 g de cascas de A. parvifolium pulverizadas, que foram extraídas com etanol, em aparelho de Soxhlet, por $12 \mathrm{~h}$. O extrato etanólico foi concentrado a vácuo fornecendo o extrato seco $(0,332 \mathrm{~g})$. Uma parte do extrato $(0,10$ g) foi dissolvida em metanol, completando-se o volume em balão volumétrico de $10 \mathrm{ml}$. Uma alíquota foi centrifugada e $3 \mu \mathrm{l}$ do sobrenadante foram injetados em cromatógrafo líquido de alta eficiência, empregando-se coluna de fase reversa (CLAE-FR).

Tomaram-se $200 \mathrm{ml}$ da tintura de pau-pereira que foram concentrados a vácuo, obtendo-se um resíduo de $0,857 \mathrm{~g}$. Parte do resíduo $(0,10 \mathrm{~g})$ foi dissolvido em metanol e completou-se o volume em balão volumétrico de $10 \mathrm{ml}$. Parte desta solução foi centrifugada e $10 \mu \mathrm{l}$ do sobrenadante foram injetados em CLAEFR. Para análise por CLAE-FR utilizou-se, como fase móvel, um gradiente linear de acetonitrila/água [10\%+0,1\% (v/v) de $\mathrm{H}_{3} \mathrm{PO}_{4}$ 
a $90 \%$, em 50 minutos], fluxo de $1 \mathrm{ml}$ por minuto e detecção no UV, em comprimento de onda de $210 \mathrm{~nm}$. Os cromatogramas das amostras foram comparados pelo tempo de retenção dos picos.

\section{Referências}

${ }^{1}$ Bolzani, V.S.; Serur, L.M.; Matos, F.J.A.; Gottlieb, O.R. Indole alkaloid evolution in Aspidosperma. Biochem. Syst. Ecol., v. 15, n. 2, p. 187-200, 1987.

2 Jácome, R.L.R.P. Estudo químico de Zeyheria montana M. e Aspidosperma parvifolium A.DC. Quantificação, por CLAE, de naftoquinonas isoladas de Z. montana. Belo Horizonte, $157 \mathrm{p}$. Dissertação de Doutorado, Instituto de Ciências Exatas, Universidade Federal Minas Gerais, 1998.

${ }^{3}$ Manske, R.H.F.; Rodrigo, R. The alkaloids. New York: Academic Press, 1965. v. VIII. p. 861, 1965.

${ }^{4}$ Lorenzi, H. Árvores Brasileiras: manual de identificação e cultivo de plantas arbóreas nativas no Brasil. São Paulo: Plantarum, Nova Odessa, p. 352, 1992.

${ }^{5}$ Wagner, H.; Bladt, S.; Zgainski, E.M. Plant drug analysis. Berlin: Springer-Verlag, p. 320, 1984.

\section{*Autor para correspondência:}

Profa. Dra. Rose Lisieux R. P. Jácome

Laboratório de Fitoquímica

Faculdade de Farmácia

Universidade Federal de Minas Gerais

Av. Olegário Maciel, 2360

CEP 30180-112 - Belo Horizonte (MG)

E-mail: lisieux@dedalus.lcc.ufmg.br.
Constituintes apolares do fruto do açaí (Euterpe oleracea M. - Arecaceae)

\section{Mantovani, I.S.B.; Fernandes, S.B.O. e Menezes, F.S.*}

Departamento de Produtos Naturais e Alimentos, Faculdade de Farmácia, Centro de Ciências da Saúde, Universidade Federal do Rio de Janeiro

\section{Resumo}

Euterpe oleracea M. (açaí) é uma palmeira economicamente importante encontrada em vários locais do Brasil. O palmito é uma iguaria bastante apreciada em todo o mundo enquanto o fruto é apenas consumido no Brasil. Esse estudo enfocou a composição química do extrato hexânico obtido de diferentes partes do fruto: o pericarpo, o endocarpo e o fruto na íntegra. Ficou comprovado não haver diferença química significativa na análise cromatográfica dos três extratos.

\begin{abstract}
Euterpe oleracea M. (açaí) is an economically important palm found in many places throughout Brazil. The heart of palm is a well known delicacy all around the world while the fruit of this palm is eaten only in Brazil. This study deals with the chemical composition of the hexanic extract obtained from the different parts of the fruit: the pericarp, the endocarp and the whole fruit. It has been comproved no chemical difference regarding fatty acids when these three extracts were analysed.
\end{abstract}

As palmeiras possuem cerca de 2500 a 3500 espécies distribuídas em 210 a 236 gêneros. A família Palmae Juss. possui um nome alternativo que é Arecaceae Schultz-Schultzenst. e geralmente inclui plantas de outras famílias. A variação no número de espécies surgiu de desacordos entre botânicos no delineamento de fronteiras de gêneros e espécies fazendo com que essa família ocupe a quarta ou quinta posição num ranking de tamanho (em números de espécies) para as Monocotiledôneas ${ }^{1,2}$. A espécie abordada nesse trabalho é a Euterpe oleracea Martius, palmeira de belo porte, cujos estipes vão de 2 a 30 m de altura, folhas longas e segmentadas, flores em espiga, frutos drupáceos e gomo terminal longo e macio que constitui o chamado palmito ${ }^{3}$. O fruto fornece através do despolpamento manual ou mecânico, o suco também conhecido como "vinho do açaí", bebida largamente consumida pela população dos estados produtores ${ }^{4,5}$. Esse trabalho teve por objetivo avaliar se há diferença na composição química, em ácidos graxos, quando comparados os extratos obtidos de diferentes partes do fruto com o fruto íntegro. 